\title{
Editorial \\ Photocatalytic Degradation of Organic Wastes in Water
}

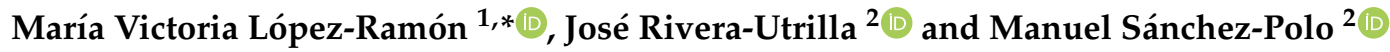 \\ 1 Department of Inorganic and Organic Chemistry, Faculty of Experimental Science, University of Jaen, \\ 23071 Jaen, Spain \\ 2 Department of Inorganic Chemistry, Faculty of Science, University of Granada, 18071 Granada, Spain; \\ jrivera@ugr.es (J.R.-U.); mansanch@ugr.es (M.S.-P.) \\ * Correspondence: mvlro@ujaen.es
}

Citation: López-Ramón, M.V.; Rivera-Utrilla, J.; Sánchez-Polo, M. Photocatalytic Degradation of Organic Wastes in Water. Catalysts 2022, 12, 114. https://doi.org/ $10.3390 /$ catal12020114

Received: 10 January 2022

Accepted: 16 January 2022

Published: 19 January 2022

Publisher's Note: MDPI stays neutral with regard to jurisdictional claims in published maps and institutional affiliations.

Copyright: (C) 2022 by the authors. Licensee MDPI, Basel, Switzerland. This article is an open access article distributed under the terms and conditions of the Creative Commons Attribution (CC BY) license (https:// creativecommons.org/licenses/by/ $4.0 /)$.
Over recent years, public concerns have arisen about environmental pollution by socalled emerging organic pollutants (EOPs) in water sources and factory effluents, because of their potentially adverse effects on human health and aquatic ecosystems. Numerous physical and biological processes have been proposed to remove pollutants from water, but they do not completely eliminate the majority of EOPs. Advanced Oxidation Processes (AOPs) based on catalytic, electrochemical, and photochemical reactions are currently available and can degrade a large number of pollutants. An important group of AOPs is formed by photocatalytic processes, in which luminous radiation electronically activates the semiconductor material that constitutes the catalyst. $\mathrm{TiO}_{2}$ is one of the materials most widely utilized as photocatalysts in water decontamination, either alone or combined with other materials that act as doping agents and/or material supports. However, this semiconductor material has certain drawbacks, including its low quantum yield and a certain tendency to recombine the electrons and positive holes generated. Hence, it is important to continue the search for new and more efficient photocatalysts that offer an improved performance. Key accomplishments to date are compiled in this Special Issue, as summarized below.

A novel 2D/2D ( $\mathrm{CaIn}_{2} \mathrm{~S}_{4} / \mathrm{BiOCl}-\mathrm{SOV}$ s) S-scheme heterojunction material was successfully prepared by a simple high-temperature calcination process combined with a solvothermal method. Zhang et al. [1] reported that the as-prepared photocatalysts achieved a highly enhanced photodegradation of phenol under visible-light irradiation with $1 \%$ CIS/BOC-SOVs heterojunction material as catalyst, generating photocatalytic activity that was 32.8-fold greater than that of pure $\mathrm{BiOCl}$. The effective separation of photogenerated electron-hole pairs in a S-scheme heterostructure system improves the photocatalytic performance of the composite material in the photocatalytic degradation process, with a significant contribution from surface oxygen vacancies (SOVs) of the heterojunction in multicomponent composite systems. The main active substances in the degradation reaction are $\mathrm{HO}^{\bullet}, \mathrm{O}_{2}{ }^{-}$, and $\mathrm{h}^{+}$. These results support 2D/2D S-scheme heterojunctions as potential candidates for the degradation of refractory pollutants.

Hernández et al. [2] prepared $\mathrm{Au}-\mathrm{TiO}_{2}$ photocatalysts with different gold contents by a microwave- and sonochemistry-assisted sol-gel method. Physicochemical characterization of the resulting photocatalysts showed a crystallite size of about $10.5 \mathrm{~nm}$ and an even morphological distribution of spherical particles produced by the sonochemistry synthesis method. A crystallite size of $8.3 \mathrm{~nm}$ was obtained with the microwave method and increased with higher Au load. These authors showed that the cyclic voltammetric response and Mott-Schottky analysis are consistent with a semiconductor material containing metallic particles and a heterophase junction of anatase and brookite with oxygen vacancies, respectively. The photocatalytic activity was assessed by paracetamol (PC) degradation in aqueous solution. The sonochemistry-synthesized photocatalysts displayed the most promising results, with improved PC removal, and a catalyst gold content of $0.7 \mathrm{wt} . \%$ was found to be optimal for this process. 
Nanoparticles with semiconductive properties have been studied for the photodegradation of organic compounds because they help to optimize the degradation process. In this way, De León Ramírez et al. [3] evaluated the performance in nitrobenzene (NB) degradation of $\mathrm{ZnO}_{2}$ nanoparticlese synthesized by a sol-gel/sonochemical method. These nanoparticles have a crystal size of $\sim 6 \mathrm{~nm}$ and cluster to form particles of $100 \mathrm{~nm}$, with good dispersion in water. The authors concluded that the optimall conditions for NB photodegradation were 30 ppm of $\mathrm{ZnO}_{2}$ and 15 ppm of $\mathrm{NB}$ at $\mathrm{pH} 2$, reaching $90 \%$ degradation in $2 \mathrm{~h}$.

Rendel and Rytwo [4] investigated the effect of electrolytes on photocatalytic degradation $\left(\mathrm{UV} / \mathrm{H}_{2} \mathrm{O}_{2}\right.$ and $\left.\mathrm{UV} / \mathrm{TiO}_{2}\right)$, using caffeine as representative of pharmaceutical and personal care products that contaminate the aquatic environment. Results showed that the efficiency of $\mathrm{UV} / \mathrm{H}_{2} \mathrm{O}_{2}$ photodegradation is strongly influenced by the ionic strength and the presence of electrolytes in the solution. $\mathrm{Cl}^{-}$electrolytes were found to optimize or reduce the efficiency of the process according to their concentration. The sole presence of $\mathrm{NaBr}$ or $\mathrm{KBr}$ produces an immediate reduction in the efficiency of the photodegradation. In summary, this work demonstrates an empirical relationship between the presence of different electrolytes and caffeine degradation rates.

Hernández-Barreto et al. [5] studied the adsorption and photocatalytic activity of activated carbon and composites with metallic oxides $\left(\mathrm{TiO}_{2}\right.$ and $\left.\mathrm{ZnO}\right)$. Their characterization revealed mesoporous filling by $\mathrm{TiO}_{2}$ and $\mathrm{ZnO}$ nanoparticles, leaving only some microporosity in their structure, and composite surface heterogeneity due to the non-homogeneous distribution of the oxides on the activated carbon surface. Surface acidity was increased with incorporation of the oxide due to its amphoteric nature. Study of the photoelectrical properties showed a decreased band-gap in comparison to pristine $\mathrm{TiO}_{2}$. $\mathrm{AC}-\mathrm{TiO}_{2}$ was found to have greater photocatalytic activity and adsorption capacity in comparison to to AC-ZnO.

The exceptional properties of graphene/metal oxide composites have attracted attention in the field of environmental remediation and water treatment. Reduced graphene oxide (rGO), a derivative of graphene oxide, is highly effective for photocatalytic reactions. When used in combination with metal oxides (e.g., $\mathrm{TiO}_{2}, \mathrm{ZnO}, \mathrm{Cu}_{2} \mathrm{O}, \mathrm{Bi}_{2} \mathrm{WO}_{6}$, etc.), it has proved to be a highly effective photocatalyst to degrade different pollutants from water and to prevent the corrosion and leaching of the metal oxide nanoparticles in water [6,7]. A series of $\mathrm{rGO} / \mathrm{Bi}[6]$ and $\mathrm{rGO} / \mathrm{TiO}_{2}$ [7] composites with varied $\mathrm{rGO}$ contents were successfully synthesized and exhaustively characterized, followed by a comparison of their structural, chemical, and electronic properties with their photocatalytic activity in the degradation of organic pollutants in aqueous solution. Fernández-Perales et al. [6] demonstrated that GO was efficaciously reduced to $\mathrm{rGO}$ and that Bi was polydispersed on the surface as a crystalline phase of $\mathrm{Bi}_{2} \mathrm{O}_{3}$. Sulfamethazine (SMZ) was used as model pollutant to evaluate the photocatalytic efficacy. The mass ratio of rGO to Bi affected the efficacy of SMZ photodegradation, and the 5\% rGO/Bi nanocomposite was the most active for SMZ degradation under solar radiation, achieving 100\% degradation after only $2 \mathrm{~h}$ of treatment. The degradation yield decreased with higher percentages of rGO. Accordingly, rGO/Bi catalysts efficiently removed SMZ with high photocatalytic activity and remained unchanged after three treatment cycles. These findings highlight the potential value of these novel composites as photocatalysts to selectively remove pollutants in water treatment plants.

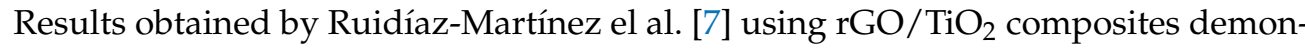
strated the efficacious reduction of GO, the formation of pure anatase phase, and the formation of $\mathrm{Ti}-\mathrm{O}-\mathrm{C}$ bonds on the composite surfaces. Experiments were performed to evaluate the effectiveness of these new materials as photocatalysts in the degradation of ethylparaben (EtP) by UV radiation. According to the band-gap energies obtained, rGO$\mathrm{TiO}_{2}$ composites behave as semiconductor materials. The highest photocatalytic activity for EtP degradation under UV radiation was achieved with the composite containing 7\% rGO, which reached $99 \%$ degradation after $40 \mathrm{~min}$ of irradiation. The authors concluded that this 
type of photoactive composite, based on $\mathrm{rGO}$ and $\mathrm{TiO}_{2}$ and with an adequate content of rGO, can be highly effective for the UV photodegradation of emerging organic pollutants (e.g., parabens) in water.

One of the challenges face in utilizing photocatalysts is the loss of metal ions from the catalyst. The likelihood of metal leakage is lower with magnetic nanoparticles because the particles can accumulate an external magnetic field. Magnetic particles with an iron oxide core are of special interest for their low cost, easy separation, and excellent reusability. In this regard, Marsooli et al. [8] successfully prepared magnetic $\mathrm{Fe}_{3} \mathrm{O}_{4} / \mathrm{ZnWO}_{4} / \mathrm{CeVO}_{4}$ nanoparticles at different molar ratios using the co-precipitation method. Those with a 1:2:1 molar ratio mediated the highly efficient photocatalytic degradation of various organic pollutants such as methyl violet under visible light and methyl orange (MO) under UV irradiation, achieving $100 \%$ degradation. When these nanoparticles were reacted in the presence of different scavengers, photogenerated $\mathrm{HO}^{\bullet}$ and ${ }^{\bullet} \mathrm{O}_{2}{ }^{-}$radicals were the main oxidative forms. The authors concluded that $\mathrm{Fe}_{3} \mathrm{O}_{4} / \mathrm{ZnWO}_{4} / \mathrm{CeVO}_{4}$ nanoparticles are potentially useful photocatalysts for the effective removal of organic pollutants from wastewater.

Altamiro-Briones et al. [9] investigated the degradation of meropenem (MER) by heterogeneous photocatalysis using $\mathrm{TiO}_{2}$ immobilized on fiberglass substrates, finding that addition of the substrates had a positive effect on the removal of this compound. SEM study showed that $\mathrm{TiO}_{2}$ was homogeneously distributed over the fiberglass matrix. Three $\mathrm{pH}$ values (4.0, 5.7, and 7.9) were tested for the treatment of MER solutions, and the best rate constants and MER removal rates were obtained at $\mathrm{pH}$ values of 4.0 and 5.7. Chemical oxygen demand and total organic carbon removal rates of $25.8 \%$ and $29.6 \%$, respectively, were achieved at $\mathrm{pH}$ 5.7. The reutilization and regeneration of the subtrates were also tested, observing that they maintained their activity until the fourth reutilization cycle.

$\mathrm{Zn}_{\mathrm{x}} \mathrm{Cd}_{1-\mathrm{x}} \mathrm{S}$ has attracted widespread interest as a solid solution photocatalyst due to its unique adjustable band-gap structure and its good stable performance. A series of ZCSs with nanosheet structures were successfully synthesized by an ultrasonication-assisted hydrothermal method [10]. All solid solutions (except for $\mathrm{x}=0.8-1.0$ ) showed greater efficiency to photocatalytically degrade $\mathrm{MO}$ solution under visible light in comparison to CdS. The highest percentage degradation was achieved with $\mathrm{Zn}_{0.3} \mathrm{Cd}_{0.7} \mathrm{~S}(92 \%)$ due to its high crystallinity and small crystallite size. The balance between band-gap structure-directed redox capacity and light absorption of $\mathrm{Zn}_{0.3} \mathrm{Cd}_{0.7} \mathrm{~S}$ accounts for its good photocatalytic performance. In this way, Yang et al. [10] contributed a novel strategy to synthesize highly efficient sulfide photocatalysts.

Rajca M. [11] examined the removal of natural organic substances (humic acid [HA] and fulvic acid [FA]) from model solutions using photocatalysis and ultrafiltration. They described the effect of two nano-titanium dioxide photocatalysts (P25 and P90) with different active surface areas on the removal of HA and FA during photocatalysis. A combined photocatalytic + ultrafiltration system was also applied, determining its effectiveness to remove $\mathrm{HA}$ and FA and studying changes in the relative permeate flux. The photocatalysis proved to be more efficient with P90 than with P25 due to its larger surface area. The efficient decomposition of organic substances was observed up to $30 \mathrm{~min}$ of solution exposure and was faster with a medium-pressure lamp than with a low-pressure lamp. The photocatalysis + ultrafiltration system was characterized by a high degree of FA removal and an improvement in hydraulic efficiency during ultrafiltration.

In conclusion, this Special Issue on "Photocatalytic Degradation of Organic Wastes in Water" offers an overview of the latest advances in the preparation and characterization of photocatalytic materials, with particular emphasis on their application in environmental remediation to remove emerging organic pollutants from waters. We trust that our compilation of key studies will serve to inspire researchers in this field.

Finally, we are grateful to all authors for their valuable contributions and to the editorial team of Catalysts for their kind suppor, making this Special Issue possible. 
Funding: This research received no external funding.

Conflicts of Interest: The authors declare no conflict of interest.

\section{References}

1. Zhang, Z.; Zhang, Y.; Han, X.; Guo, L.; Wang, D.; Lv, K. Assembly of CaIn ${ }_{2} \mathrm{~S}_{4}$ on defect-rich BiOCl for acceleration of interfacial charge separation and photocatalytic phenol degradation via S-scheme electron transfer mechanism. Catalysts 2021, 11, 1130. [CrossRef]

2. Hernández, R.; Hernández-Reséndiz, J.R.; Cruz-Ramírez, M.; Velázquez-Castillo, R.; Escobar-Alarcón, L.; Ortiz-Frade, L.; Esquivel, $\mathrm{K}$. Au- $\mathrm{TiO}_{2}$ synthesized by a microwave- and sonochemistry-assisted sol-gel method: Characterization and application as photocatalyst. Catalysts 2020, 10, 1052. [CrossRef]

3. De León Ramírez, J.I.; Reyes Villegas, V.A.; Pérez Sicairos, S.; Hernández Guevara, E.; Brito Perea, M.D.C.; Landeros Sánchez, B. Synthesis and characterization of zinc peroxide nanoparticles for the photodegradation of nitrobenzene assisted by UV-light. Catalysts 2020, 10, 1041. [CrossRef]

4. Rendel, P.M.; Rytwo, G. The effect of electrolytes on the photodegradation kinetics of caffeine. Catalysts 2020, 10, 644. [CrossRef]

5. Hernández-Barreto, D.F.; Rodriguez-Estupinán, J.P.; Moreno-Piraján, J.C.; Sierra Ramírez, R.; Giraldo, L. Adsorption and photocatalytic study of phenol using composites of activated carbon prepared from onion leaves (Allium fistulosum) and metallic oxides ( $\mathrm{ZnO}$ and $\left.\mathrm{TiO}_{2}\right)$. Catalysts 2020, 10, 574. [CrossRef]

6. Fernández-Perales, M.; Rozalen, M.; Sánchez-Polo, M.; Rivera-Utrilla, J.; López-Ramón, M.V.; Álvarez, M.A. Solar degradation of sulfamethazine using rGO/Bi composite photocatalysts. Catalysts 2020, 10, 573. [CrossRef]

7. Ruidíaz-Martínez, M.; Álvarez, M.A.; López-Ramón, M.V.; Cruz-Quesada, G.; Rivera-Utrilla, J.; Sánchez-Polo, M. Hydrothermal synthesis of $\mathrm{rGO}-\mathrm{TiO}_{2}$ composites as high-performance UV photocatalysts for ethylparaben degradation. Catalysts 2020, 10, 520. [CrossRef]

8. Marsooli, M.A.; Nasrabadi, M.R.; Fasihi-Ramandi, M.; Adib, K.; Pourmasoud, S.; Ahmadi, F.; Eghbali, M.; Nasab, A.S.; Tomczykowa, M.; Plonska-Brzezinska, M.E. Synthesis of magnetic $\mathrm{Fe}_{3} \mathrm{O}_{4} / \mathrm{ZnWO}_{4}$ and $\mathrm{Fe}_{3} \mathrm{O}_{4} / \mathrm{ZnWO}_{4} / \mathrm{CeVO}_{4}$ nanoparticles: The photocatalytic effects on organic pollutants upon irradiation with UV-Vis light. Catalysts 2020, 10, 494. [CrossRef]

9. Altamirano Briones, A.; Cóndor Guevara, I.; Mena, D.; Espinoza, I.; Sandoval-Pauker, C.; Ramos Guerrero, L.; Vargas Jentzsch, P.; Muñoz Bisesti, F. Degradation of meropenem by heterogeneous photocatalysis using $\mathrm{TiO}_{2} /$ fiberglass substrates. Catalysts 2020, 10, 344. [CrossRef]

10. Yang, L.; Zhang, M.; Liu, M.; Fan, Y.; Ben, H.; Li, L.; Fu, X.; Chen, S. Ultrasonication-assisted synthesis of $\mathrm{Zn}_{\mathrm{x}} \mathrm{Cd}_{1-\mathrm{x}} \mathrm{S}$ for enhanced visible-light photocatalytic activity. Catalysts 2020, 10, 276. [CrossRef]

11. Rajca, M. NOM (HA and FA) reduction in water using nano titanium dioxide photocatalysts (P25 and P90) and membranes. Catalysts 2020, 10, 249. [CrossRef] 